\title{
Саногенетические эффекты электромагнитного излучения миллиметрового диапазона в лечении внебольничной пневмонии
}

ГОУ ВПО "Смоленская государственная медицинская академия Росздрава": 214019, Смоленск, ул. Крупской, 28

\author{
E.V.Vvanishkina, V.G.Podoprigorova
}

\section{Sanogenetic effects of millimeter-range electromagnetic radiation in community-acquired pneumonia}

\begin{abstract}
Summary
To study sanogenetic effects of millimeter-range electromagnetic radiation in patients with community-acquired pneumonia (CAP), blood lipid peroxidation was investigated in 50 patients and 230 control healthy donors. The results showed that standard therapy of CAP does not improve disorders of free radical lipid peroxidation which were studied by direct methods of chemiluminescence and EPR-spectroscopy. More prominent clinical efficiency of millimeter-range electromagnetic radiation in combined treatment of CAP patients was associated with correction of oxidant and antioxidant disbalance and allowed to optimize results of treatment.

Key words: community-acquired pneumonia, free radical lipid peroxidation, oxidant and antioxidant status, chemiluminescence, EPR-spectroscopy, millimeter-range electromagnetic radiation.
\end{abstract}

\section{Резюме}

С целью изучения саногенетических эффектов воздействия электромагнитного излучения миллиметрового диапазона в комплексном лечении пациентов с внебольничной пневмонией (ВП) в аспекте влияния на параметры свободнорадикального перекисного окисления липидов крови были обследованы 50 пациентов и 230 здоровых доноров для определения контрольных показателей. Полученные результаты свидетельствуют о том, что стандартная терапия не устраняет нарушений процессов свободнорадикального окисления, изученных прямыми методами контроля: хемилюминесценцией и ЭПР-спектроскопией (ЭПР - электронный парамагнитный резонанс). Выраженная клиническая эффективность использования электромагнитного излучения миллиметрового диапазона в комплексном лечении больных ВП связана с коррекцией прооксидантно-антиоксидантного и антиоксидантного дисбаланса, что позволяет оптимизировать результаты лечения.

Ключевые слова: внебольничная пневмония, свободнорадикальное окисление липидов, прооксидантная система, система антиоксидантной защиты, хемилюминесценция, ЭПР-спектроскопия, электромагнитное излучение миллиметрового диапазона.

Несмотря на широкий арсенал антибактериальных средств, в России среднестатистический показатель заболеваемости внебольничной пневмонией (ВП) составляют 10-15\%о. За последние 10 лет отмечается тенденция к росту распространенности ВП среди молодых лиц, затяжному, осложненному течению и увеличению смертности [1, 2]. Все это указывает на необходимость дальнейшего совершенствования лечебных мероприятий и включения в стандарты дополнительных методов терапии, влияющих на молекулярные механизмы развития заболевания.

В настоящее время среди молекулярных механизмов развития пневмонии общепризнана роль активных форм кислорода (АФК) [3]. Известно, что в норме АФК (супероксид-анион, гидроксил, пероксид водорода, гипохлорит) играют большую роль во многих жизненно важных процессах в организме. Они участвуют в биоэнергетических процессах, поддержании гомеостаза, окислении и детоксикации экзо- и эндогенных соединений. АФК определяют защитный микробицидный потенциал фагоцитов, влияющий на иммунитет [4-6]. Однако неконтролируемая генерация АФК в ходе окислительного взрыва при несостоятельности защитной антиоксидантной системы приводит к окислительной модификации белков, нуклеиновых кислот, ферментов, к свободнорадикальному перекисному окислению липидов (СРОЛ), вызывающему повреждение клеточных мембран, что сопряжено с ингибированием трансмембранного переноса ионов, дезорганизацией работы мембранных структур, изменением клеточного метаболизма, развитием деструкции [6]. Тем не менее в настоящее время не уделяется должного внимания необходимости коррекции пероксидного и антиоксидантного дисбалансов при ВП, недостаточно изучены возможные методы коррекции, которые могут применяться с целью разрешения заболевания, профилактики хронизации процесса и развития осложнений. Большой клинический интерес представляют неинвазивные, доступные, малозатратные и эффективные технологии, которые не имеют негативных проявлений и позволяют существенно оптимизировать результаты проводимой терапии. Одним из таких приемов является воздействие электромагнитного излучения (ЭМИ) миллиметрового диапазона волн. Согласно данным литературы, первичной мишенью воздействия ЭМИ миллиметрового диапазона являются клеточные мембраны [7], при этом оно влияет на прооксидантно-антиоксидантные механизмы [8]. Однако саногенетический эффект ЭМИ 
миллиметрового диапазона на клиническое течение ВП при использовании прямых методов контроля над свободнорадикальными процессами не изучался.

Цель настоящей работы - исследование саногенетических эффектов воздействия ЭМИ миллиметрового диапазона в терапии больных ВП с позиций проксидантно-антиоксидантного гомеостаза.

\section{Материалы и методы}

Было проведено обследование и лечение 50 пациентов с ВП в возрасте от 20 до 50 лет. Диагноз верифицировали на основании анамнеза, общеклинического исследования, результатов лабораторных и инструментальных методов [1]. При госпитализации у всех больных ВП состояние было среднетяжелым. У пациентов, принимавших участие в исследовании, не было значимых сопутствующих заболеваний. Контрольные показатели свободнорадикального гомеостаза определены у 230 здоровых доноров аналогичного возрастного диапазона (группа контроля).

В зависимости от проводимой терапии после заполнения "Декларации добровольности" больные ВП были разделены на 2 группы, сопоставимые по демографическим и клинико-функциональным параметрам. Пациенты 1-й группы (сравнения, $n=25$ ) получали стандартное лечение, включающее дезинтоксикационные средства, противовоспалительные препараты, бронхо- и муколитики, один из антибактериальных препаратов (амоксициллин, амоксициллин / клавуланат, цефотаксим, цефтриаксон, цефуроксим, азитромицин, кларитромицин, левофлоксацин) в общепринятой дозе, согласно практическим рекомендациям по диагностике, лечению и профилактике ВП у взрослых [1]. В терапии пациентов 2-й группы (основной, $n=25$ ) наряду со стандартными методами использовалось воздействие ЭМИ миллиметрового диапазона, которое начинали после снижения температуры до субфебрильной или ее нормализации. Применяли установку "АМРТ-02" в режиме "качающейся" частоты и чередования волновых диапазонов (общий частотный диапазон 52-62 Ггц). Воздействовали на проекцию патологического очага в легких по задней поверхности грудной клетки в положении больного сидя с помощью контактно расположенного рупора при плотности потока излучения $\leq 10^{8} \mathrm{мBT} / \mathrm{cm}^{2}$. Время экспозиции составляло 30 мин. Курс включал в себя 10 процедур, которые проводились ежедневно, кроме выходных [9].

Прооксидантно-антиоксидантные параметры сыворотки крови исследовали прямыми методами контроля над свободнорадикальными процессами. Методом активированной родамином Ж хемилюминесценции (ХЛ) в присутствие ионов 2-валентного железа определяли уровень гидроперекисей липидов (ГПЛ) - продуктов СРОЛ - и суммарную антиокислительную активность (АОА) [10]. Измерение суммарной АОА позволяет оценить потенциальную возможность совокупного действия всех антиоксидантов в сложной биологической системе. Интен- сивность генерации АФК фагоцитирующими клетками цельной крови, характеризующую неспецифическую защиту организма, изучали с помощью люминолзависимой ХЛ [11]. Активность главных сывороточных антиоксидантов - церулоплазмина, способного перехватывать супероксидный радикал и окислять ионы 2-валентного железа в реакциях инициации СРОЛ, и трансферрина, транспортирующего ионы железа, - исследовали методом ЭПР-спектроскопии (ЭПР - электронный парамагнитный резонанс). Активность антиоксидантной системы (АОС) церулоплазмин-трансферрин определяли по отношению ЭПР-сигнала церулоплазмина к ЭПР-сигналу трансферрина, которое является интегральным показателем антирадикальной защиты в ответ на инициацию СРОЛ [12]. Для количественной оценки степени выраженности дисбаланса свободнорадикального гомеостаза использовался интегральный показатель - коэффициент К (отношение средних значений АФК (\%) к норме к средним значениям AOA (\%) к норме). При отсутствии дисбаланса $\mathrm{K}=1$ [13]. Для анализа степени выраженности антиоксидантного дисбаланса в сыворотке крови применялся коэффициент $\mathrm{K}_{1}$ - отношение AOA (\%) к норме к АОС церулоплазмин-трансферрин (\%) к норме. При отсутствии антиоксидантного дисбаланса $\mathrm{K}_{1}=1$ [13].

Статистическую обработку результатов проводили по общепринятой методике, определяя среднее арифметическое и ошибку среднего, с помощью программы Statistica 6.0. О достоверности показателей судили по t-критерию Стьюдента. Статистически достоверными считали различия при $p \leq 0,05$.

\section{Результаты и обсуждение}

В первые 5 сут. заболевания были госпитализированы $28 \%$ пациентов с ВП 1-й группы и $24 \%$ - 2-й группы. Оценка клинической эффективности проводилась по окончании антибиотикотерапии и магнитно-резонансной томографии (7-й и 14-й дни от начала исследования). Критериями оценки эффективности служили динамика клинических показателей, аускультативная картина, изменение рентгенологической картины заболевания (наличие или отсутствие инфильтрации легочной ткани) и показателей лабораторных анализов крови. Исходные клинико-функциональные параметры исследуемых групп представлены в табл. 1.

Обе группы были сопоставимы по демографическим и клинико-лабораторным параметрам, что позволило корректно провести сравнительную оценку эффективности различных методов терапии (стандартной и с применением ЭМИ миллиметрового диапазона).

Исходные параметры СРОЛ пациентов 1-й и 2-й группы представлены в табл. 2. Согласно данным ХЛ, уровень ГПЛ сыворотки крови у больных ВП 1 -й и 2-й группы достоверно не отличался $(p>0,05)$ и превышал показатели в контрольной группе $\left(p_{1}<\right.$ 0,$001 ; p_{1}<0,01$ соответственно). Суммарная АОА 
Таблица 1

Клиническая характеристика больных ВП

\begin{tabular}{|c|c|c|}
\hline Параметры & 1-я группа ( $n=25)$ & 2 группа ( $(n=25)$ \\
\hline Возраст, лет & $38,50 \pm 2,21$ & $36,00 \pm 2,97$ \\
\hline $\begin{array}{l}\text { Длительность заболевания, } \\
\text { дней }\end{array}$ & $13,00 \pm 1,97$ & $15,60 \pm 2,23$ \\
\hline Повышение $t^{\circ}, n$ (\%) & $19(76)$ & $20(80)$ \\
\hline Боли в грудной клетке, $n$ (\%) & $9(36)$ & $10(40)$ \\
\hline Одышка, $n$ (\%) & $12(48)$ & $13(52)$ \\
\hline Кашель, $n$ (\%) & $25(100)$ & $25(100)$ \\
\hline Гнойная мокрота, $n(\%)$ & $15(60)$ & $16(64)$ \\
\hline Слабость, $n$ (\%) & $25(100)$ & $25(100)$ \\
\hline $\begin{array}{l}\text { Укорочение перкуторного } \\
\text { звука, } n(\%)\end{array}$ & $23(92)$ & $24(96)$ \\
\hline $\begin{array}{l}\text { Ослабление везикулярного } \\
\text { дыхания, } n(\%)\end{array}$ & $23(92)$ & $24(96)$ \\
\hline Хрипы, $n(\%)$ & $10(40)$ & $12(48)$ \\
\hline Лейкоцитоз >8,0 × 109/л, $n(\%)$ & $9(36)$ & $8(32)$ \\
\hline Повышение СОЭ, $n$ (\%) & $14(56)$ & $17(68)$ \\
\hline \multicolumn{3}{|l|}{ Рентгенологическая картина } \\
\hline сегментарная пневмония, $n$ (\%) & $14(56)$ & $11(44)$ \\
\hline долевая пневмония, $n$ (\%) & $11(44)$ & $14(56)$ \\
\hline Затяжное течение, $n$ (\%) & $15(60)$ & $14(56)$ \\
\hline $\begin{array}{l}\text { Осложнения (экссудативный } \\
\text { плеврит, абсцедирование), } n \text { (\%) }\end{array}$ & $5(20)$ & $6(24)$ \\
\hline
\end{tabular}

Примечание: СОЭ - скорость оседания эритроцитов.

в исследуемых группах достоверно ниже, чем в группе контроля $\left(p_{1}<0,01\right)$, без статистически значимых отличий у больных 1-й и 2-й группы $(p>0,5)$. При исследовании люминолзависимой ХЛ у больных ВП было выявлено повышение интенсивности свечения цельной крови. Интенсивность генерации АФК активированными лейкоцитами достоверно превышала показатели в контрольной группе $(p<0,001)$, статистически достоверные отличия между 1-й и 2-й группой отсутствовали $(p>0,5)$. У пациентов 1-й и 2-й группы до лечения дисбаланс систем СРОЛAO3 сыворотки крови был ровным и умеренным. В 1-й группе К увеличился до 3,09; во 2-й - до 3,09. Полученные результаты согласуются с данными литературы и подтверждают нарушение свободнорадикальных процессов при ВП [14, 15].

Проведенный сравнительный анализ показал наличие корреляции между уровнем генерации АФК активированными лейкоцитами в периферической крови и уровнем ГПЛ в сыворотке крови у пациен-
Таблица 3

Клиническая характеристика больных после лечения

\begin{tabular}{|c|c|c|}
\hline Параметры & $\begin{array}{c}\text { 1-я группа } \\
(n=25)\end{array}$ & $\begin{array}{c}\text { 2-я группа } \\
(n=25)\end{array}$ \\
\hline $\begin{array}{l}\text { Сроки стационарного } \\
\text { лечения, дни }\end{array}$ & $17,80 \pm 1,46$ & $15,40 \pm 0,74$ \\
\hline Субфебрилитет, $n$ (\%) & $3(12)$ & 0 \\
\hline Кашель, $n(\%)$ & $6(24)$ & $1(4)$ \\
\hline Слабость, $n$ (\%) & $8(32)$ & $2(8)$ \\
\hline Хрипы, $n(\%)$ & $7(28)$ & 0 \\
\hline Лейкоцитоз > 8,0 × 109/ת, $n$ (\%) & $2(8)$ & $1(4)$ \\
\hline Повышение СОЭ, $n$ (\%) & $6(24)$ & $4(16)$ \\
\hline \multicolumn{3}{|l|}{ Рентгенологическая картина } \\
\hline положительная динамика, $n$ (\%) & $18(72)$ & $10(40)$ \\
\hline полное рассасывание инфильтрата, $n$ (\%) & $6(24)$ & $15(60)$ \\
\hline
\end{tabular}

тов 1-й группы $(r=0,48 ; p<0,05)$ и 2-й группы $(r=0,50 ; p<0,05)$, а также концентрацией лейкоцитов в периферической крови в 1-й и 2-й группе ( $r=0,41 ; p<0,05$ и $r=0,42 ; p<0,05$ соответственно).

При ЭПР-исследовании выявлено достоверное снижение уровня церулоплазмина и трансферрина сыворотки крови у пациентов $1-и ̆ ~\left(p_{1}>0,05 ; p_{1}<\right.$ $0,001)$ и 2-й группы $\left(p_{1}<0,001\right)$, статистически значимые различия сигналов между группами отсутствовали $(p>0,5)$. Активность АОС церулоплазминтранферрин в обеих группах также достоверно не отличалась $(p>0,5)$. Коэффициент $\mathrm{K}_{1}$ в 1-й $(0,60)$ и 2-й группах $(0,58)$ был снижен примерно в одинаковой мере, что свидетельствовало о существенном антиоксидантном дисбалансе сыворотки крови у больных ВП.

У пациентов исследуемых групп клиническое улучшение регистрировалось на 3-7-й день антибактериальной терапии: снизилась выраженность лихорадки, исчезли боли в грудной клетке, уменьшились одышка, кашель, количество мокроты и степень ее гнойности, симптомы интоксикации, улучшилось физикальное состояние легких. Клинико-лабораторные и инструментальные данные пациентов после курса антибактериальной терапии и комплексного лечения с воздействием ЭМИ миллиметрового диапазона представлены в табл. 3.

Следует отметить, что все больные ВП 2-й группы отмечали хорошую переносимость физиопроцедур, что согласуется с данными литературы [1]. После комплексного лечения с использованием ЭМИ

Таблица 2

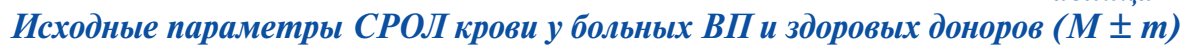

\begin{tabular}{|c|c|c|c|c|}
\hline Показатели ХЛ & Контрольная группа $(n=230)$ & 1 -я группа ( $n=25)$ & 2-я группа $(n=25)$ & $p$ \\
\hline ГПЛ, отн. ед. & $63,60 \pm 1,16(n=129)$ & $77,4 \pm 3,74^{* * *}$ & $73,00 \pm 2,58^{\star *}$ & $>0,05$ \\
\hline АОА, отн. ед. & $33,70 \pm 1,02(n=129)$ & $25,90 \pm 3,37^{\star *}$ & $25,40 \pm 2,14^{\star *}$ & $>0,5$ \\
\hline АФК, $\times 10^{6}$ Квант $/ \mathrm{c} \times 4 \pi$ & $2,10 \pm 0,09(n=91)$ & $5,00 \pm 0,49^{* * *}$ & $4,90 \pm 0,35^{\star * *}$ & $>0,5$ \\
\hline Церулоплазмин, отн. ед. & $61,10 \pm 1,43(n=85)$ & $55,30 \pm 2,85$ & $45,30 \pm 4,92^{* * *}$ & $>0,05$ \\
\hline Трансферрин, отн. ед. & $58,80 \pm 1,93(n=85)$ & $38,20 \pm 3,90 * * *$ & $35,60 \pm 3,73^{* * *}$ & $>0,5$ \\
\hline АОС церулоплазмин-трансферрин & $1,10 \pm 0,06(n=85)$ & $1,40 \pm 0,21^{*}$ & $1,40 \pm 0,19^{*}$ & $>0,5$ \\
\hline
\end{tabular}

Примечание: p - значимость различий между показателями больных 1-й и 2-й группы; $p_{1}$ - значимость различий между показателями контрольной группы и больных ВП ( ${ }^{*}-<0,05 ;$ $\left.* *-<0,01 ;{ }^{* * *}-<0,001\right)$. 
Показатели СРОЛ крови у больных ВП после лечения (M \pm m)

\begin{tabular}{|c|c|c|c|}
\hline Показатели ХЛ & 1 -я группа $(n=25)$ & 2-я группа ( $n=25)$ & $p_{2}$ \\
\hline ГПЛ, отн. ед. & $82,40 \pm 6,37^{* * *}$ & $59,90 \pm 2,52^{n}$ & $<0,01$ \\
\hline АОА, отн. ед. & $20,70 \pm 2,65^{* * *}$ & $36,20 \pm 1,93^{\wedge}$ & $<0,001$ \\
\hline АФК, $\times 10^{6}$ квант $/ \mathrm{c} \times 4 \pi$ & $4,20 \pm 0,79^{* * *}$ & $2,10 \pm 0,08^{\wedge}$ & $<0,01$ \\
\hline Церулоплазмин, отн. ед. & $46,90 \pm 7,64^{* *}$ & $50,20 \pm 5,49^{* *}$ & $>0,5$ \\
\hline Трансферрин, отн. ед. & $33,50 \pm 5,30^{* * *}$ & $37,00 \pm 4,39^{* * *}$ & $>0,5$ \\
\hline АОС церулоплазмин-транферрин & $1,30 \pm 0,23$ & $1,40 \pm 0,19^{*}$ & $>0,5$ \\
\hline
\end{tabular}

Примечание: ^ - $p<0,001$ по сравнению с исходным уровнем; * $-p<0,05 ;{ }^{* *}-p<0,01$; ** $-p<0,001$ между контрольной группой и больными ВП;

$p_{2}$ - между показателями 1-й и 2-й группы.

миллиметрового диапазона положительная клинико-рентгенологическая динамика была более выраженной (полное рассасывание воспалительного инфильтрата отмечено у большего числа больных).

Для возможного объяснения клинической эффективности и саногенетических механизмов ЭМИ миллиметрового диапазона с позиций оценки показателей свободнорадикального гомеостаза проведен раздельный анализ динамики параметров СРОЛ и АОА в группах, разделенных в зависимости от способа лечения (табл. 4).

После стандартного лечения не произошло достоверного изменения дисбаланса показателей СРОЛ. Отмечена тенденция к увеличению уровня ГПЛ $\left(p>0,5 ; p_{1}<0,001\right)$ и уменьшению суммарной AOA $\left(p>0,05 ; p_{1}<0,001\right)$ по сравнению с исходными значениями, что усугубляет нарушения в системе СРОЛ-АОЗ. Повышенный исходный уровень генерации АФК практически не изменился $\left(p>0,05 ; p_{1}<\right.$ $0,001)$, что свидетельствует о сохранении гиперпродукции АФК. В ходе ЭПР-исследования сыворотки крови выявлена тенденция к снижению сигналов сывороточных антиоксидантов, в большей степени церулоплазмина ( $\left.p>0,05 ; p_{1}<0,01\right)$, в меньшей трансферрина $\left(p>0,5 ; p_{1}<0,001\right)$. Активность АОС церулоплазмин-трансферрин практически не изменилась $(p>0,5)$, поскольку трансферрин активно проявлял свои антиоксидантные свойства на фоне снижения антиоксидантной активности церулоплазмина. В результате отмечено увеличение интеграль-

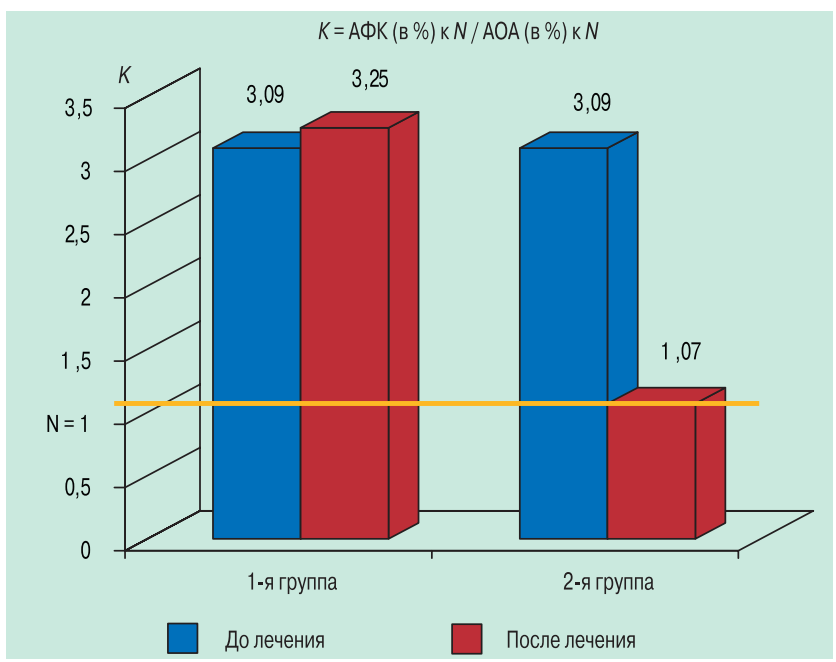

Рисунок. Динамика коэффициента К у больных ВП после лечения ного показателя дисбаланса процессов СРО сыворотки крови - коэффициента К - до 3,25 (рисунок).

Коэффициент $\mathrm{K}_{1}$ снизился до 0,50. Полученные данные свидетельствуют о том, что традиционная фармакотерапия не устраняет имеющийся при воспалительном процессе дисбаланс свободнорадикального гомеостаза, и согласуются с результатами других исследований [15]. Сохраняющийся повышенный уровень агрессивных продуктов СРОЛ на фоне депрессии антиоксидантной защиты, по мнению ряда исследователей, способствует прогрессированию заболевания и появлению осложнений [15] и объясняет замедленную динамику клинико-лабораторной и ренгенологической картины у больных ВП 1-й группы.

Возможно, более выраженную клиническую эффективность комплексного лечения больных ВП с использованием ЭМИ миллиметрового диапазона по предложенной методике объясняет позитивная динамика параметров СРОЛ. ХЛ- и ЭПР-тесты сыворотки крови у пациентов с ВП 2-й группы показали достоверное уменьшение уровня ГПЛ $(p<0,001)$ практически до контрольного значения $\left(p_{1}>0,05\right)$, суммарная АОА статистически значимо увеличилась $\left(p<0,001 ; p_{1}>0,05\right)$. В результате коэффициент $\mathrm{K}$ сыворотки крови снизился до 1,07 (рисунок), что указывает на нивелирование дисбаланса свободнорадикального перекисного гомеостаза у больных 2-й группы. Уровень генерации АФК фагоцитирующими клетками уменьшился до нормы $\left(p<0,001 ; p_{1}>\right.$ $0,5)$. Сигнал церулоплазмина имел тенденцию к увеличению $\left(p>0,5 ; p_{1}<0,01\right)$ при практически неизмененном уровне трансферрина $\left(p>0,5 ; p_{1}<0,001\right)$. Исходная повышенная активность АОС церулоплазмин-трансферрин практически не изменилась $(p>$ $0,5)$, достоверно превышая показатели в группе контроля $\left(p_{1}<0,05\right)$. Зарегистрировано увеличение коэффициента $\mathrm{K}_{1}$ до 0,83 , что отражает уменьшение антиоксидантного дисбаланса у больных 2-й группы по сравнению с исходным уровнем $(0,58)$.

\section{Заключение}

1. Применение ЭМИ миллиметрового диапазона в комплексном лечении больных ВП оптимизирует стандартную терапию и обеспечивает более выраженный положительный клинический эффект (увеличилось количество больных с полным рассасыванием воспалительного инфильтрата). 
2. ЭМИ миллиметрового диапазона в комплексном лечении корректирует нарушения прооксидантно-антиоксидантного и антиоксидантного дисбаланса, что является фундаментальной основой универсального молекулярного механизма саногенетического эффекта данной методики.

\section{Литература}

1. Внебольничная пневмония у взрослых: Практ. рекомендации по диагностике, лечению и профилактике / Чучалин А.Г., Синопальников А.И., Страчунский Л.С. и др. М.: М-Вести; 2006.

2. Metlay J.P., Fine M.J. Testing strategies in the initial management of patients with community - acguired pneumonia. Ann. Intern. Med. 2003; 138: 109-118.

3. Соодаева C.K. Окислительный стресс и антиоксидантная терапия при заболеваниях органов дыхания. Пульмонология 2006; 5: 122-126.

4. Зенков Н.К., Меньшикова Е.Б. АКМ - главное оружие фагоцитов в борьбе с микроорганизмами. В кн.: Активные формы кислорода, оксид азота, антиоксиданты и здоровье человека: Материалы конференции. Смоленск; 2005. 32-35.

5. Окислительный стресс. Прооксиданты и антиоксиданты / Меньшикова Е.Б., Ланкин В.З., Зенков Н.К. и др. М.: Фирма "Слово"; 2006.

6. Коган A.X. Фагоцитзависимые кислородные - свободнорадикальные механизмы аутоагрессии в патогенезе внутренних болезней. Вестн. РАМН 1999; 2: 3-10.

7. Бецкий О.В., Кислов В.В., Лебедева Н.Н. Миллиметровые волны и живые системы. М.: Сайнс-пресс; 2004.
8. Иванишкина Е.В. Применение микроволновой (биоинформационной) резонансной терапии в лечении язвенной болезни двенадцатиперстной кишки: Дис. ... канд. мед. наук. М.; 2001.

9. Подопригорова В.Г., Иванишкина Е.В., Хибин Л.С. Способ лечения язвенной болезни двенадцатиперстной кишки. Пат. № 2214291 от 20.10.03.

10. Шерстнев М.П. Методика регистрации активированной родамином Ж хемилюминесценции плазмы и сыворотки крови в присутствии ионов двухвалентного железа. Вопр. хемилюминесценц. 1990; 1: 19-20.

11. Шерстнев М.П. Методика регистрации люминолзависимой хемилюминесценции цельной крови стимулированной кристаллами сульфата бария. Вопр. хемилюминесценц. 1991; 2: 20-22.

12. Gutteridge $J$. Inhibition of the fenton reactive by the protein ceruloplasmin and other copper complexes assesment of ferroxidase and radical scavenging activities. Chem. Biol. Interact. 1985; 56 (1): 113-120.

13. Подопригорова В.Г. Оксидативный стресс и язвенная болезнь. М.: ОАО "Изд-во "Медицина"; 2004.

14. Трубников Г.В., Варшавский Б.Я, Галактионова Л.П. и др. Оксидантный и антиоксидантный статус больных хроническим бронхитом и пневмонией. Пульмонология 2002; 4: 37-40.

15. Фархутдинов У.Р. Эффективность $\alpha$-токоферола при внебольничной пневмонии. Пульмонология 2007; 3: 99-102.

\section{Информация об авторах}

Иванишкина Елена Владимировна - к. м. н., доцент кафедры пропедевтики внутренних болезней СГМА; тел.: (4812) 55-35-20

Подопригорова Вера Георгиевна - д. М. Н., проф., зав. кафедрой пропедевтики внутренних болезней СГМА, зав. ПНИЛ клинической биофизики и антиоксидантной терапии; тел. / факс: (4812) 64-59-64; e-mail: oxygen05@yandex.ru 